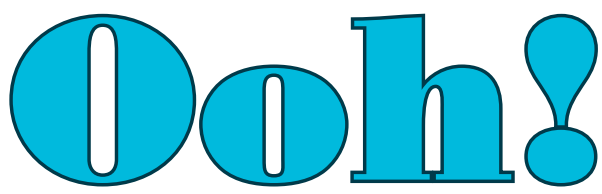

\title{
can I have one of those?
}

\section{With the season of dental conferences and exhibitions upon us, Stephen Hancocks assesses all those 'freebies'.}

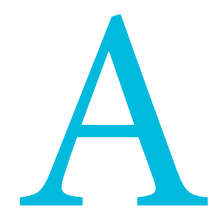

part from bits that are thrust upon us, what is it that makes us hoard items that we just obviously don't need and in any event could buy for next to nothing if we really chose to? It must have something to do with the same psychology that makes us buy things from car boot sales, or auctions. Things you don't really want, like badly painted porcelain figurines of ladies on swings with bowls of cherries, or special clips to keep your baseball cap on, or gadgets with magnets and squeegee mops to clean the outside of windows in high apartment blocks (when you actually live in a bungalow). But there is a 'must have' desperation about it all. That driving force, surging through you that says 'you have to have the woman with the cherries, because if you don't, that smelly, bald bloke standing next to you is going to get it instead. Do you really want him to have it when it truly should be yours?'

The rational answer is, of course, 'yes, he's very welcome to the ghastly ornament, the cheap hat fastener and the tinny mop. But the irrational urge always ensures that we end up with stuff that, in the cold hard light of day, we cannot understand what possibly possessed us to practically fight for. Why did we deny that young hygienist the plastic hamster which squirts mouthwash out of its pouches?

And the same is inexplicably true about booths or stands where trinkets are being given away, pencil-erasers with 'smile-lots-more' filling material being advertised on them. Into the dental nurse's ribs goes the elbow, a technician with an arm in a sling is less than politely shoved out of the way and 'yes' it is in your grasp! Why does it

\section{'Why did we deny that young hygienist the \\ plastic hamster which}

\section{squirts mouthwash?'}

not occur to you that, until you bring the prize triumphant into the practice the next day to a chorus of team members reminding you, no one uses pencils anymore, you're computerised?

Conference bags, or brief cases, or attaché grips, or document conveyances, or whatever the latest PR-speak name is for a folded and stitched thing to carry even more essential marketing items are called, are slightly different. These are the crème-de-la-crème of the freebie hierarchy, the hand polished, plastic-effect leatherette with the sponsor company's logo lightly melted at an ever-so-slightly skewed angle onto the outside top right-hand corner. If you're lucky it will have your name on it (if you're very lucky it will be spelt correctly) so that when you put it down beside your chair at lunchtime there is at least a sporting chance of you getting yours back again. The worry being that other people pick up such rubbish at these events instead of your discerning choice of hand-crafted, quality items. Hmm.

Then again most of us have a small, sad and dusty conference bag graveyard. For some it is the bottom of a wardrobe in the spare room. For others, the cupboard under the stairs, the loft in the practice, or with the twice-used aerobic muscle-builder stowed with guilty awkwardness under the bed. Wherever this all-but final resting place is, it is discovered from time to time with a sigh and a desperate panicky reflex about what on earth to do with its jaded memorial of yesterday's slept-through lectures. They, for they are rarely buried singly, are somehow too potentially 'good' just to throw away, especially as, at most, they are likely to have had about two days' worth of being nonchalantly carried. Then again, what other use is there for them?

You pick it up and feel it. It's lumpy. Why? You lift the slightly clammy plastic flap and peer in. The sections inside have gone a bit sticky and RECEPTION need to be prised apart. A reply-paid survey form enquiring about diamond burs and offering a week's all expenses paid holiday for two in Corfu if returned before June 2003 unfurls, blinking in the unaccustomed light. Somewhere, lurking down at the bottom, a squashed sample of homeopathic toothpaste has burst, hardened and gone back to nature. Still, at least it seals the fate of that particular bag: dustbin time and another decision made. What's really needed is a great big bag that you could use to store all the rest of the bags in. Ooh, now that that would be worth having. If ever you see one of those grab one, quick. 